\title{
Enhancing Access to Yoga for Older Male Veterans After Cancer: Examining Beliefs About Yoga
}

\author{
Elizabeth J. Auguste; Rachel E. Weiskittle, PhD; Stephanie J. Sohl, PhD; Suzanne C. Danhauer, PhD; Kelly Doherty; \\ Aanand D. Naik, MD; and Jennifer Moye, PhD
}

\begin{abstract}
Background: Yoga is an effective clinical intervention for cancer survivors. Most studies of the positive effects of yoga on cancer patients report on predominantly middle-aged women with breast cancer. Less is known about the use of yoga in older adults, veterans, and those from diverse racial or ethnic backgrounds.
\end{abstract}

Methods: We examined strategies to enhance access to yoga in older veterans after cancer, focusing on education (study 1) and intervention (study 2). Study 1 included 110 participants with a median (SD) age of 64.9 (9.4) years who were mostly male $(99 \%)$ cancer survivors who were interviewed 12 months after their cancer diagnosis. Study 2 included 28 participants with a median (SD) age of 69.2 (10.9) years who were mostly male (96\%) cancer survivors who participated in a yoga program within 3 years of their cancer diagnosis. Standardized interviews assessed interest in and barriers to yoga while self-reporting assessed health-related quality of life and beliefs about yoga.
Results: In study 1, interest in yoga increased from 5.5 to $31.8 \%\left(\chi^{2}=22.25, P<.001\right)$ following education. In openended questions 4 themes related to negative beliefs or barriers emerged: lack of knowledge or skepticism, disinterest or dislike, physical health barriers, and logistical barriers. In study 2 , beliefs were more positive following intervention for expected benefits $(t=4.44, P<.001)$, discomfort $(t=4.92$, $P<.001)$, and social norms $(t=4.38, P<.001)$ related to yoga. Physical function improved after participation in a yoga class, especially for those with higher beliefs in yoga prior to class. Age was not associated with beliefs about yoga in either sample.

Conclusions: A portion of older veterans who are cancer survivors were interested in yoga but faced access barriers. Implications for practice and research include increasing knowledge about yoga benefits and addressing physical health and logistical barriers to enhance access to yoga for older veterans.
Author affiliations can be found at the end of the article.

Correspondence: Jennifer Moye (jennifer.moye@va.gov)

Fed Pract. 2021;38(10). Published online October 12. doi:10.12877/fp.0180
Y oga is an effective clinical intervention for cancer survivors. Studies indicate a wide range of benefits, including improvements in physical functioning, emotional well-being and overall quality of life..$^{1-7}$ Two-thirds of National Cancer Institute designated comprehensive cancer centers offer yoga on-site. ${ }^{8}$ Yoga is endorsed by the National Comprehensive Cancer Network and American Society of Clinical Oncology for managing symptoms, such as cancer-related anxiety and depression and for improving overall quality of life. ${ }^{9,10}$

Although the positive effects of yoga on cancer patients are well studied, most published research in this area reports on predominantly middle-aged women with breast cancer. ${ }^{11,12}$ Less is known about the use of yoga in other groups of cancer patients, such as older adults, veterans, and those from diverse racial or ethnic backgrounds. This gap in the literature is concerning considering that the majority of cancer survivors are aged 60 years or older, and veterans face unique risk factors for cancer associated with herbicide exposure (eg, Agent Orange) and other military-related noxious exposures. ${ }^{13,14}$ Older cancer survivors may have more difficulty recovering from treatment-related adverse effects, making it especially important to target recovery efforts to older adults. ${ }^{15}$ Yoga can be adapted for older cancer survivors with agerelated comorbidities, similar to adaptations made for older adults who are not cancer survivors but require accommodations for physical limitations. ${ }^{16-20}$ Similarly, yoga programs targeted to racially diverse cancer survivors are associated with improved mood and wellbeing in racially diverse cancer survivors, but studies suggest community engagement and cultural adaptation may be important to address the needs of culturally diverse cancer survivors. ${ }^{21-23}$

Yoga has been increasingly studied within the Veterans Health Administration (VHA) for treatment of posttraumatic stress disorder (PTSD) and has been found effective in reducing symptoms through the use of traumainformed and military-relevant instruction as well as a military veteran yoga teacher. ${ }^{24-26}$ This work has not targeted older veterans or cancer survivors who may be more difficult to recruit into such programs, but who would nevertheless benefit.

Clinically, the VHA whole health model 
TABLE 1 Demographic and Clinical Characteristics

\begin{tabular}{|c|c|c|}
\hline & $\begin{array}{l}\text { Observational Study } \\
\qquad(\mathrm{N}=110)\end{array}$ & $\begin{array}{l}\text { Interventional Study } \\
\quad(\mathbf{N}=\mathbf{2 8})\end{array}$ \\
\hline Age, mean (SD) [range], y & $64.9(9.4)[41-88]$ & $69.2(10.9)[55-87]$ \\
\hline \multicolumn{3}{|l|}{ Sex, No. (\%) } \\
\hline Male & 109 (99.1) & $27(96.4)$ \\
\hline Female & $1(0.9)$ & $1(3.6)$ \\
\hline \multicolumn{3}{|l|}{ Race/ethnicity, No. (\%) } \\
\hline White, non-Hispanic & $78(70.9)$ & $25(89.3)$ \\
\hline Black/African American & $20(18.2)$ & $3(10.7)$ \\
\hline Hispanic & $9(8.2)$ & 0 \\
\hline \multicolumn{3}{|l|}{ Education, No. (\%) } \\
\hline Grade school (1-8 y) & $2(1.8)$ & $1(3.6)$ \\
\hline Some high school (9-12 y) & $13(11.8)$ & $6(21.4)$ \\
\hline High school graduate & $40(36.4)$ & $5(17.9)$ \\
\hline College courses/ degree & $43(39.1)$ & $14(50.0)$ \\
\hline Postgraduate courses/degree & $12(10.9)$ & $2(7.1)$ \\
\hline \multicolumn{3}{|l|}{ Cancer types, No. (\%) } \\
\hline Blood & 0 & $4(14.3)$ \\
\hline Colorectal & $56(50.9)$ & $5(17.9)$ \\
\hline Esophageal/gastric & $11(10.0)$ & $2(7.1)$ \\
\hline Genitourinary & 0 & $10(35.7)$ \\
\hline Lung & 0 & $4(14.3)$ \\
\hline Head and neck & $43(39.1)$ & $2(7.1)$ \\
\hline Thyroid & 0 & $1(3.6)$ \\
\hline \multicolumn{3}{|c|}{ American Joint Committee on Cancer stage, No. (\%) } \\
\hline 1 & $32(29.1)$ & $8(28.6)$ \\
\hline 2 & $28(25.5)$ & $10(35.7)$ \\
\hline 3 & $25(22.7)$ & $7(25.0)$ \\
\hline 4 & $25(22.7)$ & $3(10.7)$ \\
\hline
\end{tabular}

is providing increased opportunities for veterans to engage in holistic care including yoga. ${ }^{27}$ Resources include in-person yoga classes (varies by facility), videos, and handouts with practices uniquely designed for veterans or wounded warriors. As clinicians increasingly refer veterans to these programs, it will be important to develop strategies to engage older veterans in these services.

One important strategy to enhancing access to yoga for older veterans is to consider beliefs about yoga. Beliefs about yoga or general expectations about the outcomes of yoga may be critical to consider in expanding access to yoga in underrepresented groups. Beliefs about yoga may include beliefs about yoga improving health, yoga being difficult or producing discomfort, and yoga involving specific social norms.$^{28}$ For example, confidence in one's ability to perform yoga despite discomfort predicted class attendance and practice in a sample of 32 breast cancer survivors. ${ }^{29}$ Relatedly, positive beliefs about the impact of yoga on health were associated with improvements in mood and quality of life in a sample of 66 cancer survivors. ${ }^{30}$
The aim of this study was to examine avenues to enhance access to yoga for older veterans, including those from diverse backgrounds, with a focus on the role of beliefs. In the first study we investigate the association between beliefs about and barriers to yoga in a group of older cancer survivors, and we consider the role of demographic and clinical variables in such beliefs and how education may alter beliefs. In alignment with the whole health model of holistic health, we posit that yoga educational materials and resources may contribute to yoga beliefs and work to decrease these barriers. We apply these findings in a second study that enrolled older veterans in yoga and examining the impact of program participation on beliefs and the role of beliefs in program outcomes. In the discussion we return to consider how to increase access to yoga to older veterans based on these findings.

\section{METHODS}

Study 1 participants were identified from VHA tumor registries. Eligible patients had head and neck, esophageal, gastric, 
TABLE 2 Variables Associated With Beliefs About Yoga

\begin{tabular}{lcccccc} 
& \multicolumn{2}{c}{$\begin{array}{c}\text { Expected } \\
\text { Benefits }\end{array}$} & \multicolumn{2}{c}{$\begin{array}{c}\text { Expected } \\
\text { Discomfort }\end{array}$} & \multicolumn{2}{c}{$\begin{array}{c}\text { Expected } \\
\text { Social Norms }\end{array}$} \\
& Study 1 & Study 2 & Study 1 & Study 2 $^{\text {b }}$ & Study 1 & Study 2 $^{\text {b }}$ \\
\hline Age & -.10 & .00 & .10 & -.03 & -.05 & -.06 \\
\hline Education & .19 & .28 & .06 & $.60^{\mathrm{c}}$ & $.22^{\mathrm{d}}$ & .35 \\
\hline Race $^{\mathrm{c}}$ & $.20^{\mathrm{d}}$ & -- & $.20^{\mathrm{d}}$ & -- & .03 & -- \\
\hline Stage & $-.27^{\mathrm{e}}$ & -.01 & .11 & -.02 & $.19^{\mathrm{d}}$ & -.10 \\
\hline $\begin{array}{l}\text { Physical } \\
\text { function }\end{array}$ & .07 & $.75^{\mathrm{e}}$ & $.20^{\mathrm{d}}$ & $.50^{\mathrm{e}}$ & .14 & $.49^{\mathrm{d}}$ \\
\hline Anxiety & -.02 & .24 & -.18 & -.01 & -.13 & -.07 \\
\hline$F$ & $2.53^{\mathrm{d}}$ & $6.80^{\mathrm{d}}$ & $3.12^{\mathrm{e}}$ & $5.49^{\mathrm{e}}$ & $2.98^{\mathrm{d}}$ & 2.24 \\
\hline$R^{2}$ & .13 & .61 & .16 & .55 & .15 & .33
\end{tabular}

aReverse scored so that higher is less discomfort or perceived negative social norms. ${ }^{b}$ Race was not included as an independent variable in study 2 due to small cell sample size.

'0, White; 1, Black/African American, Hispanic, or other person of color. ${ }^{\mathrm{d}} P<.05$.

${ }^{\mathrm{e}} P<.01$. come to a yoga class?") Responses were transcribed verbatim and entered into a database for qualitative analysis. Subsequently, participants completed standardized measures of health-related quality of life and beliefs about yoga as described below.

Study 2 participants were identified from VHA tumor registries and a cancer support group. Eligible patients had a diagnosis of cancer (any type except basil cell carcinoma) within the previous 3 years and were excluded if they were in hospice care, had dementia, or had a psychotic spectrum disorder. Participants completed face-to-face semistructured interviews with a trained interviewer before and after participation in an 8 -week yoga group that met twice per week. Complete protocol methods are described elsewhere. ${ }^{16}$ This paper focuses on 28 of the 37 enrolled patients for whom we have complete pre- and postclass interview data. We previously reported on adaptations made to yoga in our pilot group of 14 individuals, who in this small sample did not show statistically significant changes in their quality of life from before to after the class. ${ }^{16}$ This analysis includes those 14 individuals and 14 who participated in additional classes, focusing on beliefs, which were not previously reported.

\section{Measures}

Participants reported their age, gender, ethnicity (Hispanic/Latino or not), race, and level of education. Information about the cancer diagnosis, American Joint Committee on Cancer (AJCC) cancer stage, and treatments was obtained from the medical record. The Physical Function and Anxiety Subscales from the Patient-Reported Outcomes Measurement Information System were used to measure health-related quality of life (HRQoL) ${ }^{32-34}$ Items are rated on a Likert scale from 1 (not at all) to 5 (very much).

The Beliefs About Yoga Scale (BAYS) was used to measure beliefs about the outcomes of engaging in yoga. ${ }^{28}$ The 11 -item scale has 3 factors: expected health benefits ( 5 items), expected discomfort (3 items), and expected social norms (3 items). Items from the expected discomfort and expected social norms are reverse scored so that a higher score indicates more positive beliefs. To reduce participant burden, in study 1 we selected 1 
item from each factor with high factor loadings in the original cross-validation sample. ${ }^{28}$ It would improve my overall health (Benefit, factor loading $=.89$ ); I would have to be more flexible to take a class (Discomfort, factor loading $=.67)$; I would be embarrassed in a class (Social norms, factor loading $=.75$ ). Participants in study 2 completed the entire 11-item scale. Items were summed to create subscales and total scales.

\section{Analysis}

Descriptive statistics were used in study 1 to characterize participants' yoga experience and interest. Changes in interest pre- and posteducation were evaluated with $\chi^{2}$ comparison of distribution. The association of beliefs about yoga with 3 levels of interest (yes, no, maybe) was evaluated through analysis of variance (ANOVA) comparing the mean score on the summed BAYS items among the 3 groups. The association of demographic (age, education, race) and clinical factors (AJCC stage, physical function) with BAYS was determined through multivariate linear regression.

For analytic purposes, due to small subgroup sample sizes we compared those who identified as non-Hispanic White adults to those who identified as African American/ Hispanic/other persons. To further evaluate the relationship of age to yoga beliefs, we examined beliefs about yoga in 3 age groups ( $40-59$ years $[\mathrm{n}=24]$; $60-69$ years $[\mathrm{n}=58]$; $70-89$ years $[n=28]$ ) using ANOVA comparing the mean score on the summed BAYS items among the 3 groups. In study 2, changes in interest before and after the yoga program were evaluated with paired $t$ tests and repeated ANOVA, with beliefs about yoga prior to class as a covariate. The association of demographic and clinical factors with BAYS was determined as in the first sample through multivariate linear regression, except the variable of race was not included due to small sample size (ie, only 3 individuals identified as persons of color).

Thematic analysis in which contentrelated codes were developed and subsequently grouped together was applied to the data of 110 participants who responded to the open-ended survey questions in study 1 to further illuminate responses to closedended questions. ${ }^{35}$ Transcribed responses to
FIGURE 1 Interest in Yoga Before and After Education in Older Male Cancer Survivors $(\mathrm{N}=110)$

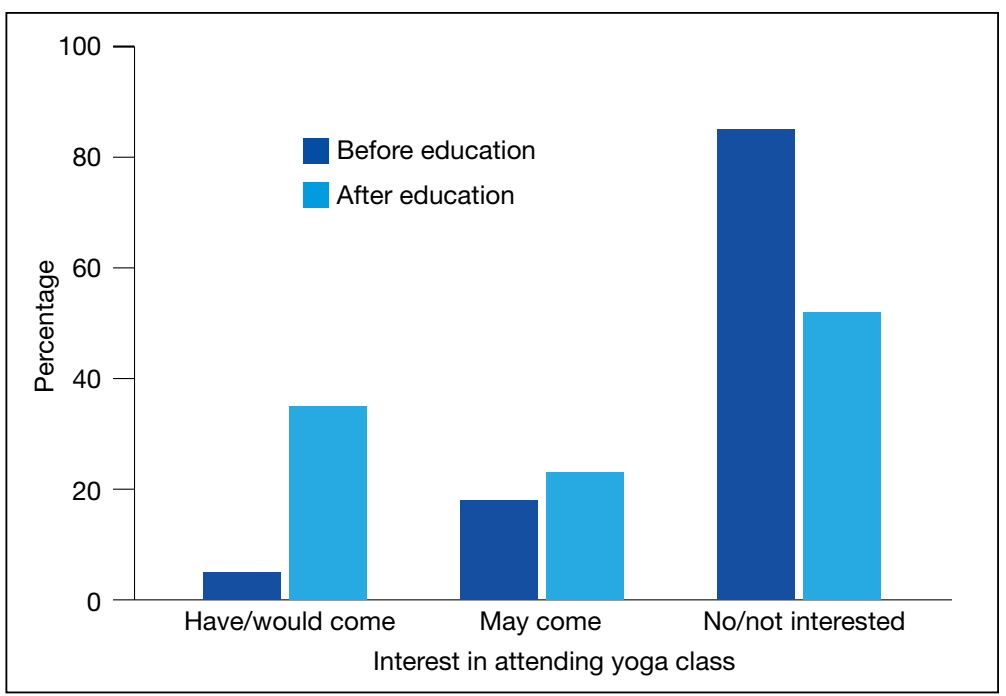

Before education, participants were asked whether they "have used yoga since cancer"; postassessment, participants were asked whether they would come to a class at the US Department of Veterans Affairs. Maybe response refers to those who indicated they might come; distributions are significantly different $\left(\chi^{2}=22.25, P<.001\right)$.

the open-ended questions were transferred to a spreadsheet. An initial code book with code names, definitions, and examples was developed based on an inductive method by one team member (EA) ${ }^{35}$ Initially, coding and tabulation were conducted separately for each question but it was noted that content extended across response prompts (eg, responses to question 2 "What might make you more likely to come?" were spontaneously provided when answering question 1), thus coding was collapsed across questions. Next, 2 team members (EA, KD) coded the same responses, meeting weekly to discuss discrepancies. The code book was revised following each meeting to reflect refinements in code names and definitions, adding newly generated codes as needed. The process continued until consensus and data saturation was obtained, with 90\% intercoder agreement. Next, these codes were subjected to thematic analysis by 2 team members (EA, KD) combining codes into 6 overarching themes. The entire team reviewed the codes and identified 2 supra themes: positive beliefs or facilitators and negative beliefs or barriers.

Consistent with the concept of reflexivity in qualitative research, we acknowledge the influence of the research team members on the qualitative process. ${ }^{36}$ The primary coding 
TABLE 3 Qualitative Themes Related to Positive or Negative Beliefs About Yoga

\begin{tabular}{|c|c|c|}
\hline Themes & Definitions & Exemplars \\
\hline \multicolumn{3}{|c|}{ Positive belief/facilitator } \\
\hline $\begin{array}{l}\text { Expectation that } \\
\text { yoga would be } \\
\text { helpful }(n=38)\end{array}$ & $\begin{array}{l}\text { Yoga would be new, } \\
\text { interesting, or would help } \\
\text { physical health and mental } \\
\text { health. }\end{array}$ & $\begin{array}{l}\text { Would participate to help [me] cope with the overall pain and } \\
\text { help [my] overall mind. } \\
\text { Anything that quiets the mind and body would be great. } \\
\text { I don't think yoga is a physical thing. It's more mental. } \\
\text { Think it would be funny... a stress relief. }\end{array}$ \\
\hline $\begin{array}{l}\text { Openness to } \\
\text { observation or } \\
\text { participation } \\
(n=24)\end{array}$ & $\begin{array}{l}\text { General openness toward } \\
\text { participating or at least } \\
\text { observing a class, including } \\
\text { factors that enhance openness } \\
\text { like peer or gender group. }\end{array}$ & $\begin{array}{l}\text { Would think about it after treatment. } \\
\text { For better companionship, fellowship...a veteran wouldn't } \\
\text { feel out of place. Veterans would have more in common [and } \\
\text { be] more at ease. } \\
\text { Would come just to see if it would reduce the stress. }\end{array}$ \\
\hline \multicolumn{3}{|c|}{ Negative beliefs/barriers } \\
\hline $\begin{array}{l}\text { Lack of } \\
\text { knowledge or } \\
\text { skepticism } \\
(n=25)\end{array}$ & $\begin{array}{l}\text { Responses reflecting lack of } \\
\text { knowledge or skepticism } \\
\text { toward yoga, including } \\
\text { absence of opinion. }\end{array}$ & $\begin{array}{l}\text { [I have] no idea what yoga is. } \\
\text { Would be a little apprehensive. } \\
\text { [Want] more information about the class, yoga itself, and } \\
\text { who is teaching it. }\end{array}$ \\
\hline $\begin{array}{l}\text { Disinterest or } \\
\text { dislike }(n=31)\end{array}$ & $\begin{array}{l}\text { Statement that they would not } \\
\text { like or would not attend a class. }\end{array}$ & $\begin{array}{l}\text { Wouldn't want to sit in a class to try and understand what it } \\
\text { would be like. } \\
\text { [Would] feel strange and out of place. } \\
\text { No. }\end{array}$ \\
\hline $\begin{array}{l}\text { Physical health } \\
\text { barriers }(n=11)\end{array}$ & $\begin{array}{l}\text { Mention of a physical health } \\
\text { problem perceived to be a } \\
\text { barrier. }\end{array}$ & $\begin{array}{l}\text { [Don't] have the flexibility. } \\
\text { Just my physical well-being. I'm tired/stressed. Every day is } \\
\text { a challenge when you can't see well. }\end{array}$ \\
\hline $\begin{array}{l}\text { Logistical } \\
\text { barriers }(n=30)\end{array}$ & $\begin{array}{l}\text { Mention of logistical barrier } \\
\text { such as affordability, time, and } \\
\text { location/transportation. }\end{array}$ & $\begin{array}{l}110 \text { miles [to the nearest VA facility] is too far to drive for } \\
\text { yoga. } \\
\text { Work schedule and timing would have to be worked out. } \\
\text { I don't want to do the traveling. That's the only thing that } \\
\text { won't sell-people don't want to do the traveling. They } \\
\text { should come to your house and do it. }\end{array}$ \\
\hline
\end{tabular}

team (EA, KD) are both researchers and employees of Veterans Affairs Boston Healthcare System who have participated in other research projects involving veterans and qualitative analyses but are not yoga instructors or yoga researchers.

\section{RESULTS}

\section{Study 1}

The sample of 110 military veterans was mostly male (99.1\%) with a mean (SD) age of 64.9 (9.4) years (range, 41-88)(Table 1). The majority (70.9\%) described their racel ethnicity as White, non-Hispanic followed by Black/African American (18.2\%) and Hispanic $(8.2 \%)$ persons; $50.0 \%$ had no more than a high school education. The most common cancer diagnoses were colorectal (50.9\%), head and neck (39.1\%), and esophageal and gastric $(10.0 \%)$ and ranged from AJCC stages I to IV.

When first asked, the majority of partici- pants (78.2\%) reported that they were not interested in yoga, $16.4 \%$ reported they might be interested, and 5.5\% reported they had tried a yoga class since their cancer diagnosis. In contrast, $40.9 \%$ used exercise, $32.7 \%$ used meditation, $14.5 \%$ used physical or occupational therapy, and $11.8 \%$ used massage therapy since their cancer diagnosis.

After participants were provided the brief scripted education about yoga, the level of interest shifted: $46.4 \%$ not interested, $21.8 \%$ interested, and $31.8 \%$ definitely interested, demonstrating a statistically significant shift in interest following education $\left(\chi^{2}=22.25\right.$, $P<.001$ ) (Figure 1 ). Those with the most positive beliefs about yoga were most likely to indicate interest. Using the BAYS 3-item survey, the mean (SD) for the definitely interested, might be interested, and not interested groups was 15.1 (3.2), 14.1 (3.2), and $12.3(2.5)$, respectively $(F=10.63$, $P<.001)$. 
A multivariable regression was run to examine possible associations between participants' demographic characteristics, clinical characteristics, and beliefs about yoga as measured by the 3 BAYS items (Table 2). Higher expected health benefits of yoga was associated with identifying as African American, Hispanic, or other identity and having a lower stage of cancer; lower concern for expected discomfort was associated with identifying as African American, Hispanic, or other identity and higher physical function. Lower concern about expected social norms was associated with higher education and having a higher stage of cancer. Age was not associated with any of the BAYS factors. In followup analysis, beliefs about yoga did not differ by age group (40-59 years: mean, 13.3, SD, 2.9; 60-69 years: mean, 13.4, SD , 3.2; 70-89 years: mean, 14.1, SD, 3.2).

Six themes were identified in qualitative analysis of semistructured interviews reflecting older veterans' beliefs about yoga, which were grouped into the following suprathemes of positive vs negative beliefs (Figure 2). Exemplar responses appear in Table 3.

\section{Study 2 Intervention Sample}

This sample of 28 veterans was mostly male (96.4\%) with a mean (SD) age of 69.2 (10.9) years (range, 57-87). The majority (89.3\%) described their race as White, followed by Black/African American (10.7\%); no participants self-identified in other categories for race/ethnicity. Twelve veterans (42.9\%) had no more than a high school education. The most common cancer diagnosis was genitourinary (35.7\%) and the AJCC stage ranged from I to IV.

We employed information learned in study 1 to enhance access in study 2 . We mailed letters to 278 veterans diagnosed with cancer in the previous 3 years that provided education about yoga based on study 1 findings. Of 207 veterans reached by phone, $133(64 \%)$ stated they were not interested in coming to a yoga class; 74 (36\%) were interested, but 30 felt they were unable to attend due to obstacles such as illness or travel. Ultimately 37 (18\%) veterans agreed and consented to the class, and 28 (14\%) completed postclass surveys.

In multivariate regression, higher expected health benefits of yoga were associ-
FIGURE 2 Themes Reflecting Interest in Yoga in Sample of Older Male Cancer Survivors $(N=110)$

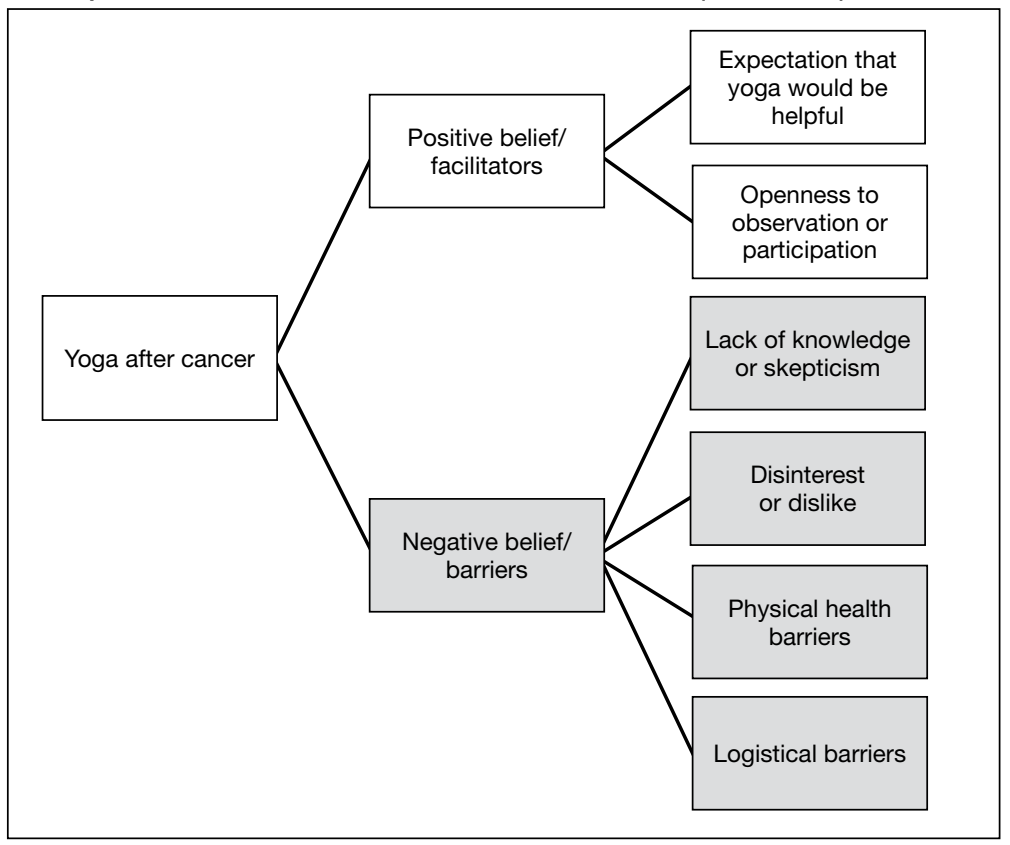

ated with higher physical function, lower concern about expected discomfort was also associated with higher physical function as well as higher education; similarly, lower concern about expected social norms was associated with higher physical function. Age was not associated with any of the BAYS factors.

Beliefs about yoga improved from before to after class for all 3 domains with greater expected benefit and lower concerns about discomfort or social norms: expected benefit (mean difference, $5.3 ; t=4.44, P<.001$ ), expected discomfort (mean difference, $3.0 ; t=$ $4.92, P<.001$ ), expected social norms (mean difference, $3.5 ; t=4.38, P<.001$ ). Physical function improved from before the class to afterwards (mean difference, $7.5 ; t=3.97$, $P<.001)$ but there were no changes in anxiety (mean difference, $0.6 ; t=0.76, P=$ .46). Beliefs about yoga moderated changes in physical function, such that those with higher beliefs experienced a greater improvement in physical function $(F=15.24$, $P<.001)$.

\section{DISCUSSION}

Yoga is an effective clinical intervention for addressing some long-term adverse effects in cancer survivors, although the body of 
research focuses predominantly on middle aged, female, White, college-educated breast cancer survivors. There is no evidence to suggest yoga would be less effective in other groups, but it has not been extensively studied in survivors from diverse subgroups. Beliefs about yoga are a factor that may enhance interest in yoga interventions and research, and measures aimed at addressing potential beliefs and fears may capture information that can be used to support older cancer survivors in holistic health. The aims of this study were to examine beliefs about yoga in 2 samples of older cancer survivors who received VHA care. The main findings are (1) interest in yoga was initially low and lower than that of other complementary or exercise-based interventions, but increased when participants were provided brief education about yoga; (2) interest in yoga was associated with beliefs about yoga with qualitative comments illuminating these beliefs; (3) demographic characteristics (education, race) and physical function were associated with beliefs about yoga; and (4) positive beliefs about yoga increased following a brief yoga intervention and was associated with improvements in physical function.

Willingness to consider a class appeared to shift for some older veterans when they were presented brief information about yoga that explained what is involved, how it might help, and that it could be done from a chair if needed. These findings clearly indicated that when trying to enhance participation in yoga in clinical or research programs, it will be important that recruitment materials provide such information. This finding is consistent with the qualitative findings that reflected a lack of knowledge or skepticism about benefits of yoga among some participants. Given the finding that physical function was associated with beliefs about yoga and was also a prominent theme in qualitative analyses, when referring older veterans to yoga it may be useful to explicitly state that yoga may enhance some aspects of physical function and can be adapted for level of physical function or pain limitations. The finding that beliefs about yoga were associated with education also suggests that materials should be presented at all levels of education.

Age was not associated with beliefs about yoga in either study. Importantly, in a more detailed study 1 follow-up analysis, beliefs about yoga were equivalent for aged $>70$ years compared with those aged 40 to 69 years. It is not entirely clear why older adults have been underrepresented in studies of yoga in cancer survivors. However, older adults are vastly underrepresented in clinical trials for many health conditions, even though they are more likely to experience many diseases, including cancer. ${ }^{37} \mathrm{~A}$ new National Institutes of Health policy requires that individuals of all ages, including older adults, must be included in all human subjects research unless there are scientific reasons not to include them. ${ }^{38}$ It is therefore imperative to consider strategies to address underrepresentation of older adults.

Qualitative findings here suggest it will be important to consider logistical barriers including transportation and affordability as well as adaptations requested by older adults (eg, preferences for older teachers). ${ }^{18}$ It may also be useful to offer yoga interventions taught by older veterans, such as in Veteranto-Veteran programs, and veteran-specific resources available through VHA Whole Health program..$^{24,26,27}$ Researchers should consider interventions that address investigator reluctance to include older adults in clinical trials, including comorbidities, ageism, and practical barriers. ${ }^{39}$ These considerations may be especially applicable now that research on the efficacy of yoga has matured and effectiveness studies are now needed.

Although our sample was small, we also found that adults from diverse racial and ethnic backgrounds had more positive beliefs about yoga, such that this finding should be interpreted with caution. Similar to older adults, individuals from diverse racial and ethnic groups are also underrepresented in clinical trials and may have lower access to complementary treatments. Cultural and linguistic adaptations and building community partnerships should be considered in both recruitment and intervention delivery strategies. ${ }^{40}$

We learned that education about yoga may increase interest and that it is possible to recruit older veterans to yoga class. Nevertheless, in study 2, our rate of full participation was low, with only about 1 in 10 participating. Additional efforts to enhance beliefs about yoga and to address 
logistical barriers (offering telehealth yoga) are needed to best reach older veterans.

\section{Limitations}

These findings have several limitations. First, participants were homogeneous in age, gender, race/ethnicity and veteran status, which provides a window into this understudied population but limits generalizability and our ability to control across populations. Second, the sample size limited the ability to conduct subgroup and interaction analyses, such as examining potential differential effects of cancer type, treatment, and PTSD on yoga beliefs or to consider the relationship of yoga beliefs with changes in quality of life before and after the yoga intervention in study 2. Additionally, age was not associated with beliefs about yoga in these samples that of mostly older adults. We were able to compare middle-aged and older adults but could not compare beliefs about yoga to adults aged in their 20s and 30s. Last, our study excluded people with dementia and psychotic disorders. Further research is needed to examine yoga for older cancer survivors who have these conditions.

\section{CONCLUSIONS}

Education that specifically informs potential participants about yoga practice, potential modifications, and potential benefits, as well as adaptations to programs that address physical and logistical barriers may be useful in increasing access to and participation in yoga for older Veterans who are cancer survivors.

\section{Acknowledgments/Funding}

The authors have no financial or personal relationships to disclose. This work was supported by the US Department of Veterans Affairs (VA) Rehabilitation Research and Development Service. This material is the result of work supported with resources and the use of facilities at the VA Boston Healthcare System, Bedford VA Medical Center, and Michael E. DeBakey VA Medical Center in Houston, Texas. We thank the members of the Veterans Cancer Rehabilitation Study (Vetcares) Research teams in Boston and in Houston and the veterans who have participated in our research studies and allow us to contribute to their health care.

\section{Author affiliations}

Elizabeth Auguste is a Research Assistant; Rachel Weiskittle is an Advanced Fellow; Kelly Doherty is a Health Science Specialist; and Jennifer Moye is Associate Director for Education and Evaluation; all at US Department of Veterans Affairs (VA) New England Geriatric Research Education and Clinical Center, VA Boston Healthcare System in Massachusetts. Stephanie Sohl is a Assistant Professor, and Suzanne Danhauer is a Professor and Director of Faculty Well-Being \& Resilience, both at the Department of Social Sciences \& Health Policy, Division of Public Health Sciences, Wake Forest School of Medicine in Winston Salem, North Carolina. Aanand Naik is Chief of Implementation Science at the VA Health Services Research and Development Center for Innovations in Quality, Effectiveness and Safety at the Michael E. DeBakey VA Medical Center and a Professor and Robert Luchi, MD Chair in Geriatric Medicine at the Baylor College of Medicine in Houston, Texas. Rachel Weiskittle is a Research Fellow and Jennifer Moye is a Professor, both at the Department of Psychiatry, Harvard Medical School.

\section{Author disclosures}

The authors report no actual or potential conflicts of interest with regard to this article.

\section{Disclaimer}

The opinions expressed herein are those of the authors and do not necessarily reflect those of Federal Practitioner, Frontline Medical Communications Inc., the US Government, or any of its agencies.

\section{References}

1. Mustian KM, Sprod LK, Janelsins M, et al. Multicenter, randomized controlled trial of yoga for sleep quality among cancer survivors. J Clin Oncol. 2013;31(26):3233-3241. doi:10.1200/JCO.2012.43.7707

2. Chandwani KD, Thornton B, Perkins GH, et al. Yoga improves quality of life and benefit finding in women undergoing radiotherapy for breast cancer. J Soc Integr Oncol. 2010;8(2):43-55.

3. Erratum: Primary follicular lymphoma of disguised as multiple miliary like lesions: A case report and review of literature. Indian J Pathol Microbiol. 2018;61(4):643. doi:10.4103/0377-4929.243009

4. Eyigor S, Uslu R, Apaydın S, Caramat I, Yesil H. Can yoga have any effect on shoulder and arm pain and quality of life in patients with breast cancer? A randomized, controlled, single-blind trial. Complement Ther Clin Pract. 2018;32:4045. doi:10.1016/j.ctcp.2018.04.010

5. Loudon A, Barnett T, Piller N, Immink MA, Williams AD. Yoga management of breast cancer-related lymphoedema: a randomised controlled pilot-trial. BMC Complement Altern Med. 2014;14:214. Published 2014 Jul 1. doi:10.1186/1472-6882-14-214

6. Browning KK, Kue J, Lyons F, Overcash J. Feasibility of mind-body movement programs for cancer survivors. Oncol Nurs Forum. 2017;44(4):446-456. doi:10.1188/17.ONF.446-456

7. Rosenbaum MS, Velde J. The effects of yoga, massage, and reiki on patient well-being at a cancer resource center. Clin J Oncol Nurs. 2016;20(3):E77-E81. doi:10.1188/16.CJON.E77-E81

8. Yun H, Sun L, Mao JJ. Growth of integrative medicine at leading cancer centers between 2009 and 2016: a systematic analysis of $\mathrm{NCl}$-designated comprehensive cancer center websites. J Natl Cancer Inst Monogr. 2017;2017(52):Igx004. doi:10.1093/jncimonographs/lgx004

9. Sanft T, Denlinger CS, Armenian S, et al. NCCN guidelines insights: survivorship, version 2.2019. J Natl Compr Canc Netw. 2019;17(7):784-794. doi:10.6004/jnccn.2019.0034

10. Lyman $\mathrm{GH}$, Greenlee H, Bohlke K, et al. Integrative therapies during and after breast cancer treatment: ASCO endorsement of the SIO clinical practice guideline. J Clin Oncol. 2018;36(25):2647-2655. doi:10.1200/JCO.2018.79.2721

11. Culos-Reed SN, Mackenzie MJ, Sohl SJ, Jesse MT, Zahavich AN, Danhauer SC. Yoga \& cancer interventions: a review of the clinical significance of patient reported outcomes for cancer survivors. Evid Based Complement Alternat Med. 2012;2012:642576. doi:10.1155/2012/642576

12. Danhauer SC, Addington EL, Cohen L, et al. Yoga for symptom management in oncology: a review of the evidence base and future directions for research. Cancer. 2019;125(12):1979-1989. doi:10.1002/cncr.31979 
13. Siegel RL, Miller KD, Jemal A. Cancer statistics, 2019. CA Cancer J Clin. 2019;69(1):7-34. doi:10.3322/caac.21551

14. US Department of Veterans Affairs. Veterans' diseases associated with Agent Orange. Updated June 16, 2021. Accessed September 22, 2021. https://www.publichealth. va.gov/exposures/agentorange/conditions

15. Deimling GT, Arendt JA, Kypriotakis G, Bowman KF. Functioning of older, long-term cancer survivors: the role of cancer and comorbidities. J Am Geriatr Soc. 2009;57(supp 2):S289-S292. doi:10.1111/j.1532-5415.2009.02515.x

16. King K, Gosian J, Doherty K, et al. Implementing yoga therapy adapted for older veterans who are cancer survivors. Int J Yoga Therap. 2014;24:87-96.

17. Wertman A, Wister AV, Mitchell BA. On and off the mat: yoga experiences of middle-aged and older adults. Can J Aging. 2016;35(2):190-205. doi:10.1017/S0714980816000155

18. Chen KM, Wang HH, $\mathrm{Li} \mathrm{CH}$, Chen MH. Community vs. institutional elders' evaluations of and preferences for yoga exercises. J Clin Nurs. 2011;20(7-8):1000-1007. doi:10.1111/j.1365-2702.2010.03337.x

19. Saravanakumar P, Higgins IJ, Van Der Riet PJ, Sibbritt D. Tai chi and yoga in residential aged care: perspectives of participants: A qualitative study. J Clin Nurs. 2018;27(2324):4390-4399. doi:10.1111/jocn. 14590

20. Fan JT, Chen KM. Using silver yoga exercises to promote physical and mental health of elders with dementia in longterm care facilities. Int Psychogeriatr. 2011;23(8):12221230. doi:10.1017/S1041610211000287

21. Taylor TR, Barrow J, Makambi K, et al. A restorative yoga intervention for African-American breast cancer survivors: a pilot study. J Racial Ethn Health Disparities. 2018;5(1):6272. doi:10.1007/s40615-017-0342-4

22. Moadel AB, Shah C, Wylie-Rosett J, et al. Randomized controlled trial of yoga among a multiethnic sample of breast cancer patients: effects on quality of life. J Clin Oncol. 2007;25(28):4387-4395. doi:10.1200/JCO.2006.06.6027

23. Smith SA, Whitehead MS, Sheats JQ, Chubb B, AlemaMensah E, Ansa BE. Community engagement to address socio-ecological barriers to physical activity among African American breast cancer survivors. J Ga Public Health Assoc. 2017;6(3):393-397. doi:10.21633/jgpha.6.312

24. Cushing RE, Braun KL, Alden C-layt SW, Katz AR. Military-Tailored Yoga for Veterans with Post-traumatic Stress Disorder. Mil Med. 2018;183(5-6):e223-e231. doi:10.1093/milmed/usx071

25. Davis LW, Schmid AA, Daggy JK, et al. Symptoms improve after a yoga program designed for PTSD in a randomized controlled trial with veterans and civilians. Psychol Trauma. 2020;12(8):904-912. doi:10.1037/tra0000564

26. Chopin SM, Sheerin CM, Meyer BL. Yoga for warriors: An intervention for veterans with comorbid chronic pain and PTSD. Psychol Trauma. 2020;12(8):888-896. doi:10.1037/tra0000649

27. US Department of Veterans Affairs. Whole health. Updated September 13, 2021. Accessed September 22, 2021. https://www.va.gov/wholehealth

28. Sohl SJ, Schnur JB, Daly L, Suslov K, Montgomery GH. Development of the beliefs about yoga scale. Int $J$ Yoga
Therap. 2011;(21):85-91.

29. Cadmus-Bertram L, Littman AJ, Ulrich CM, et al. Predictors of adherence to a 26-week viniyoga intervention among post-treatment breast cancer survivors. J Altern Complement Med. 2013;19(9):751-758. doi:10.1089/acm.2012.0118

30. Mackenzie MJ, Carlson LE, Ekkekakis P, Paskevich DM, Culos-Reed SN. Affect and mindfulness as predictors of change in mood disturbance, stress symptoms, and quality of life in a community-based yoga program for cancer survivors. Evid Based Complement Alternat Med. 2013;2013:419496. doi:10.1155/2013/419496

31. Naik AD, Martin LA, Karel M, et al. Cancer survivor rehabilitation and recovery: protocol for the Veterans Cancer Rehabilitation Study (Vet-CaRes). BMC Health Serv Res. 2013;13:93. Published 2013 Mar 11. doi:10.1186/1472-6963-13-93

32. Northwestern University. PROMIS Health Organization and the PROMIS Cooperative Group. PROMIS Short Form v2.0 - Physical Function 6b. Accessed September 24, 2021. https://www.healthmeasures.net/index .php?option=com_instruments\&view=measure\&id $=793 \&$ Itemid $=992$

33. Northwestern University. PROMIS Health Organization and the PROMIS Cooperative Group. PROMIS Short Form v1.0 - Anxiety 6a. Accessed September 24, 2021. https://www. healthmeasures.net/index.php?option=com_instruments\& $\mathrm{V}$ iew=measure\&id $=145 \&$ ltemid $=992$

34. Northwestern University. PROMIS Health Organization and the PROMIS Cooperative Group. PROMIS-43 Profile v2.1. Accessed September 24, 2021. https://www .healthmeasures.net/index.php?option=com_instruments\& view $=$ measure\&id $=858 \&$ ltemid $=992$

35. Todd NJ, Jones SH, Lobban FA. "Recovery" in bipolar disorder: how can service users be supported through a self-management intervention? A qualitative focus group study. J Ment Health. 2012;21(2):114-126. doi:10.3109/09638237.2011.621471

36. Finlay L. "Outing" the researcher: the provenance, process, and practice of reflexivity. Qual Health Res. 2002;12(4):531545. doi:10.1177/104973202129120052

37. Herrera AP, Snipes SA, King DW, Torres-Vigil I, Goldberg DS, Weinberg AD. Disparate inclusion of older adults in clinical trials: priorities and opportunities for policy and practice change. Am J Public Health. 2010;10(suppl 1):S105-S112. doi:10.2105/AJPH.2009.162982

38. National Institutes of Health. Revision: NIH policy and guidelines on the inclusion of individuals across the lifespan as participants in research involving human subjects. Published December 19, 2017. Accessed September 22, 2021. https://grants.nih.gov/grants/guide/notice-files/NOT -OD-18-116.html

39. Townsley CA, Selby R, Siu LL. Systematic review of barriers to the recruitment of older patients with cancer onto clinical trials. J Clin Oncol. 2005;23(13):3112-3124. doi:10.1200/JCO.2005.00.141

40. Vuong I, Wright J, Nolan MB, et al. Overcoming barriers: evidence-based strategies to increase enrollment of underrepresented populations in cancer therapeutic clinical trials-a narrative review. $J$ Cancer Educ. 2020;35(5):841849. doi:10.1007/s13187-019-01650-y 